\title{
LAPAROSCOPIC PREGNANCY DIAGNOSIS AND UTERINE FLUID RECOVERY IN SWINE
}

\author{
D. E. WILDT, C. B. MORCOM AND W. R. DUKELOW \\ Endocrine Research Unit, Michigan State University, \\ East Lansing, Michigan 48824, U.S.A.
}

(Received 17th December 1974)

The technique of laparoscopy has been routinely used for repeated ovarian observation in the gilt (Wildt, Fujimoto, Spencer \& Dukelow, 1973) as well as other species (Jewett \& Dukelow, 1972; Rawson \& Dukelow, 1973; Seeger, 1973; Snyder \& Dukelow, 1974). In addition to its advantage for serial observations of ovarian morphology with minimal stress to the animal, laparoscopy has been found to be a practical substitute for laparotomy in other research areas.

There are several reports of the use of pregnancy diagnosis techniques in swine (Walker, 1967; O'Reilly, 1967; Mather, Diehl \& Tumbleson, 1970; Lindahl, Martin \& Dziuk, 1972; Diehl \& Day, 1973), but these procedures are not accurate until 20 days after mating and do not provide an indication of the number of ovulations or of the uterine and ovarian morphology.

Recently, the biochemistry of uterine fluids of swine and the relationship to the incidence of embryonic mortality has been studied (Murray, Bazer, Wallace \& Warnick, 1972; Knight, Bazer \& Wallace, 1974). So far, however, collection of uterine fluid has not been achieved consecutively in the same animal without some form of chronic cannulation (Iritani, Sato \& Nishikawa, 1974).

The present studies involved twenty pre- or post-pubertal gilts used for determination of ovulation or uterine fluid recovery procedures and twentynine postpubertal mated animals used for pregnancy diagnosis studies. All gilts were of the Yorkshire, Hampshire or Yorkshire-Hampshire crossbred type and were fed a $13 \%$ corn-soy ration at $1.1 \mathrm{~kg} /$ animal/day.

The laparoscopic equipment and procedure used in this laboratory has been described previously (Wildt et al., 1973). It involves use of a 5-mm 130 degree paediatric laparoscope, fibre optic cable and Model 4000 projector light source (Richard Wolf Co.). Laparoscopy in the pig, as with most species, is a mid-ventral procedure and is performed after disinfecting the posterior abdominal region. Gilts were immobilized by an intravenous injection of sodium pentobarbitone (Halatal Solution: Jen-Sal Laboratories) at a level of 13 to $25 \mathrm{mg} / \mathrm{kg}$ body weight.

Pregnancy diagnosis and the effects of pregnancy on reproductive tract morphology during early gestation were studied with laparoscopy. Twenty mature gilts, mated twice on Day 2 of oestrus to one of two boars, were subjected to laparoscopy at various times of pregnancy. Nine pregnant gilts mated 
similarly served as controls. All gilts were killed between Days 40 and 45 of gestation. The reproductive tracts were recovered, observed for pregnancy and the fetuses were measured and weighed. Laparoscopic observations included examination of the gross uterine morphology and ovarian luteal and follicular tissue. When pregnancy failed, luteal regression could be observed as early as Day 12 after mating with subsequent follicular development occurring rapidly at Day 15 or soon after. Definite uterine coloration and motility changes related to endogenous hormone alterations were observed. In non-gravid gilts, the uterine horns were hyperaemic and there were uterine peristaltic contractions presumably due to follicular development and oestrogen secretion after Day 15 of the cycle. Uterine contractions were observed in all mature gilts, pregnant and cyclic, during the luteal phase of the cycle and the peristalses were of less magnitude and duration than those during oestrogen-dominated stages of the cycle. Although contractions were observed progressing in both directions along the horn, there was a tendency for increased contractions from the cervix towards the oviducts during the oestrogenic phase in cyclic gilts and the converse during the early luteal phase. This agrees with an earlier report based on observations in sheep at laparotomy (Hawk \& Bolt, 1974).

Pregnancy was easily detected in the five gilts examined during the 4th and 5th week of gestation (Days 28 to 33) because of the large size of the reproductive tract. In some cases, however, ovarian observation was hindered due to difficulty in manipulating the tract. Reproductive status was correctly predicted in ten gilts examined between Days 12 and 20 of gestation; six were pregnant. Correct predictions were made for only two of five gilts examined 7 days after mating. These results agree well with those of Phillippo, Swapp, Robinson \& Gill (1971) who used laparoscopy in sheep to diagnose pregnancy and determine the number of ovulation sites.

Table 1. Embryonic mortality, fetal weights and crown-torump measurements in controls and gilts undergoing laparoscopy

\begin{tabular}{|c|c|c|c|}
\hline & $\begin{array}{c}\text { Control } \\
\text { gilts } \\
(\text { Mean } \pm \text { S.E. })\end{array}$ & $\begin{array}{c}\text { Gilts } \\
\text { undergoing } \\
\text { laparoscopy } \\
(\text { Mean } \pm S . E .)\end{array}$ & Significance \\
\hline $\begin{array}{l}\text { \% Embryonic mortality* } \\
\text { Fetal weight }(\mathrm{g}) \\
\text { Grown-to-rump length (mm) }\end{array}$ & $\begin{array}{c}34 \cdot 0 \pm 7 \cdot 7 \\
6 \cdot 63 \pm 0 \cdot 27 \\
12 \cdot 17 \pm 1 \cdot 20\end{array}$ & $\begin{array}{r}41 \cdot 9 \pm 10.9 \\
6.41 \pm 0.53 \\
11.93 \pm 0.90\end{array}$ & $\begin{array}{l}\text { N.S. } \\
\text { N.S. } \\
\text { N.S. }\end{array}$ \\
\hline
\end{tabular}

N.S. Not significantly different from controls.

* Calculated from numbers of fetuses and CL.

Nine pregnant control gilts were compared with gilts undergoing laparoscopy to determine the incidence of embryonic mortality, which normally approximates 35 to $40 \%$ (Wrathall, 1971). Fetal death was calculated from the numbers of normal fetuses and CL found at slaughter, and is recorded in Table 1 . The gilts undergoing laparoscopy had an $8 \%$ increase in fetal mortality, but this difference was not statistically significant. Mean fetal weights and crown-torump measurements were not different from those in the control group. 
In five animals, CL were counted on both ovaries at laparoscopy and compared with the actual number observed at slaughter. There was no significant difference between the total numbers of CL observed with laparoscopy (56) and the number observed directly (60) indicating that this technique can be used quite accurately to determine the number of ovulations in the pig.

Laparoscopy was also used to collect uterine fluid throughout the oestrous cycle. An accessory trocar cannula was inserted laterally from the mid-line through the abdominal wall, the trocar was removed and laparoscopic grasping forceps (Richard Wolf Co.) inserted into the abdominal cavity. The uterus was grasped with the forceps and held in position while a $7 \cdot 6-\mathrm{cm} 15$-gauge needle was inserted through the abdominal wall at a site anterior to the point of cannulation. After insertion of the needle into the uterine horn, polyethylene tubing (PE 90:Clay Adams) with the terminal end sealed and small perforations along $4 \mathrm{~cm}$ of its length was inserted through the shaft of the needle and into the uterine lumen (Text-fig. 1). The cannulation needle was withdrawn and the cannula was left in the uterine horn. The examination table was lowered from the normal $30^{\circ}$ angle to a level position to allow pooling of the flushing medium

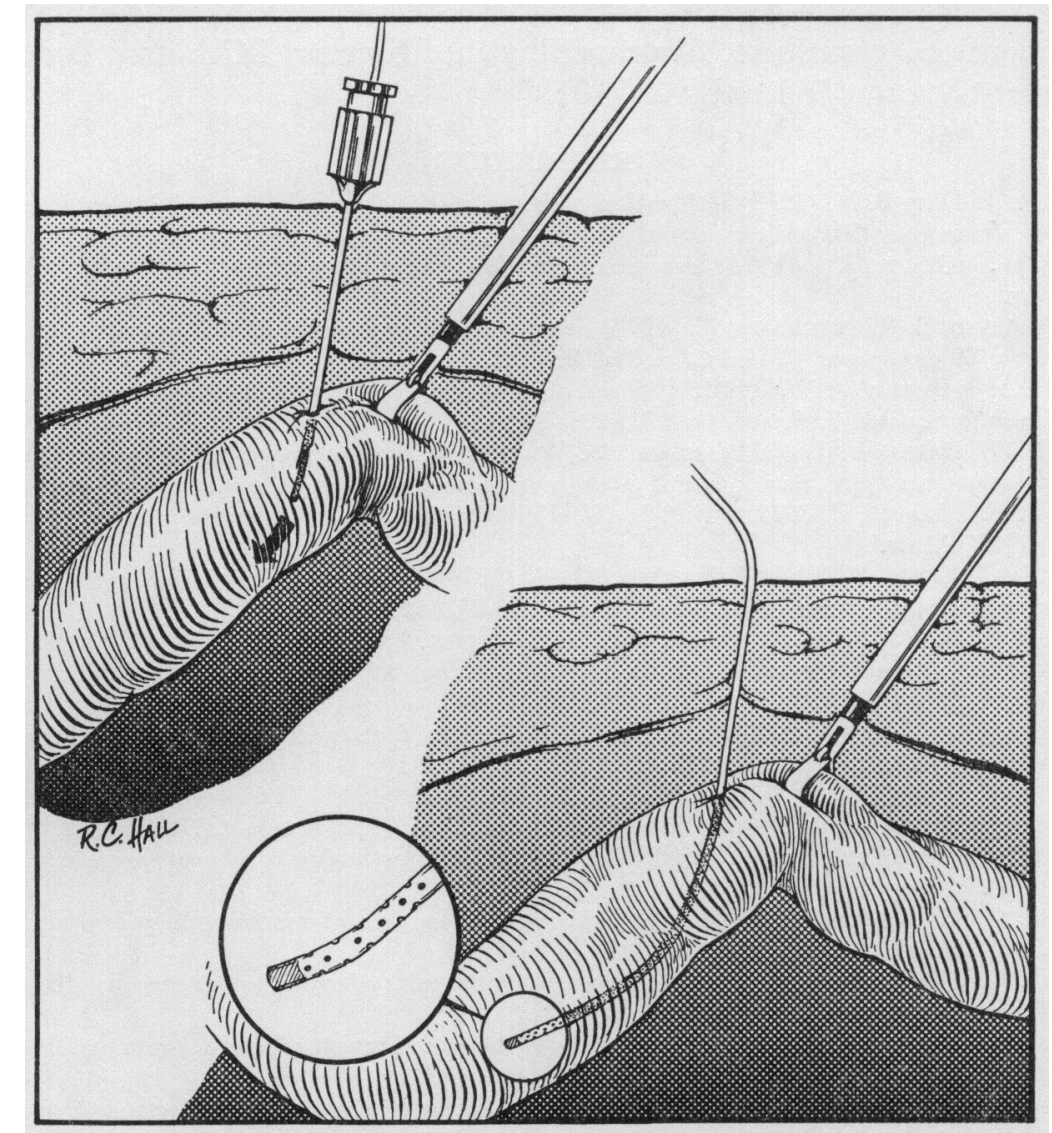

TEXT-FIG. 1. Diagram (left) of the uterus of a gilt being grasped with forceps and the insertion of a 15-gauge needle. Diagram (right) showing the needle removed, leaving only the polyethylene tubing in utero. 
after injection. Sterile saline $(6$ to $10 \mathrm{ml}$ ), was injected through the tubing and then immediately aspirated. Recovery rates of aspirate normally varied between 33 and $50 \%$. Termination of the procedure involved withdrawing the cannula from the uterus as well as all laparoscopic and accessory equipment. Subsequent examination with the laparoscope demonstrated little or no haemorrhage from the cannula insertion site after the tubing was removed. No uterine infections were observed in any animals undergoing cannulation.

Laparoscopy has been found to be a unique tool for swine research since it allows observation of the reproductive tract with little or no adverse physical effects on either the cyclic or pregnant animal and provides a practical method of diagnosing pregnancy, determining ovulation numbers, and studying uterine morphology and activity. The technique also provides the most practical method for collecting repeated uncontaminated samples of uterine fluids during any stage of the reproductive cycle.

The authors wish to thank Mr Richard C. Hall, medical illustrator, and $\mathrm{Mr}$ David A. Snyder and Mr James L. Spencer for their technical assistance.

This research was supported by U.S.P.H.S. Career Development Award No. 1-KD4-HD35,306 and a cooperative research agreement with the U.S. Department of Agriculture. Approved by the Director, Michigan Agricultural Experiment Station Journal No. 7101.

\section{REFERENCES}

DIEHL, J. R. \& DAY, B. N. (1973) Utilization of frozen sections with the vaginal biopsy technique for early pregnancy diagnosis in swine. 7. Anim. Sci. 37, 114-117.

HAwk, H. W. \& Bolt, D. J. (1974) Uterine motility in ewes in vivo and in vitro. F. Anim. Sci. 39, 281, Abstr.

Iritani, A., Sato, E. \& Nishikawa, Y. (1974) Secretion rates and chemical composition of oviduct and uterine fluids in sows. F. Anim. Sci. 39, 582-588.

JeWEtT, D. A. \& Dukelow, W. R. (1972) Serial observations of follicular morphology near ovulation in Macaca fassicularis. F. Reprod. Fert. 31, 287--290.

Knight, J. W., Bazer, F. W. \& WALlace, H. W. (1974) Effect of progesterone induced increase in secretory activity on development of the porcine conceptus. F. Anim. Sci. 39, 743-746.

Lindahl, I. L., Martin, P. \& DziUk, P. L. (1972) Early diagnosis of pregnancy in sows. F. Anim. Sci. 35, 1120, Abstr.

Mather, E. G., Diehl, J. R. \& Tumbleson, M. E. (1970) Pregnancy diagnosis in swine utilizing the vaginal biopsy technique. 7. Am. vet. med. Ass. 157, 1522-1527.

Murray, F. A., Bazer, F. W., Wallace, H. D. \& WARnick, A. C. (1972) Quantitative and qualitative variation in the secretion of protein by the porcine uterus during the oestrous cycle. Biol. Reprod. 7, 314-320.

O'Reilly, P. J. (1967) Studies on the vaginal epithelium of the sow and its application to pregnancy diagnosis. Irish vet. F. 21, 234-235.

Phillippo, M., Swapp, G. H., Robinson, J. J. \& Gill, J. G. (1971) The diagnosis of pregnancy and estimation of foetal numbers in shecp by laparoscopy. J. Reprod. Fert. 27, 129-132.

Rawson, J. M. R. \& Dukelow, W. R. (1973) Observation of ovulation in Macaca fascicularis. 7. Reprod. Fert. 34, 187-190.

SEEGER, K. (1973) Die Laparoskopie, eine Technik zur Routineuntersuchung des Genitaltrakts beim Schaf. Tierärztl. Prax. 1, 295-299.

SNYDER, D. A. \& DukELOW, W. R. (1974) Laparoscopic studies of ovulation, pregnancy diagnosis, and follicle aspiration in sheep. Theriogenology, 2, 142-147.

WALKER, D. (1967) Diagnosis of pregnancy in pigs by examination of vaginal mucosa. Vet. Rec. 81, $648-650$.

Wrathald, A. E. (1971) Prenatal survival in pigs. Part 1. Ovulation rate and its influence on prenatal survival and litter size in pigs. Commonwealth Agricultural Bureaux, England.

Wildt, D. E., Fujimoto, S., Spencer, J. L. \& Dukelow, W. R. (1973) Direct ovarian observation in the pig by means of laparoscopy. F. Reprod. Fert. 35, 541-543. 